\title{
Cidadania, representações sociais e o trabalho de catadores
}

\section{Citizenship, Social Representations and Waste Pickers' Work}

\section{Jane M. Mazzarino* Shirlei Mendes da Silva*}

\begin{abstract}
Resumo: O presente artigo é resultado de um trabalho desenvolvido com catadores de material reciclável, no qual se analisa a relação dos catadores de resíduos sólidos domésticos com seu universo de trabalho, a fim de compreender quais possibilidades de inclusão e construção da cidadania podem ser vislumbradas. Realizou-se um estudo comparativo entre catadores do município de Estrela/ RS, divididos em dois grupos: os trabalhadores da Unidade de Triagem de Lixo (UTL) e catadores de rua que atuam individualmente. A metodologia é qualitativa. As narrativas das entrevistas foram tratadas por meio da análise de conteúdo temática. Conclui-se que os catadores transformam-se em novos atores sociais da cadeia produtiva dos resíduos sólidos, mas o processo de construção de cidadania ainda é precário, uma vez que os catadores permanecem sem seus direitos fundamentais básicos assegurados.
\end{abstract}

Palavras-chave: Catadores. Cidadania. Representações Sociais.

\begin{abstract}
This article is the result of a study carried out with waste pickers which aims to analyze the relation of waste pickers and their work in order to understand the possibilities of inclusion and how citizenship can be constructed. A comparative study was developed among the waste pickers from Estrela/RS divided into two groups: the workers from the Garbage Sorting Unit (in the English acronym) and the waste pickers who work on their own on the streets. The study used a qualitative methodology which included the content analysis of interviews. The outcomes of the study demonstrate that waste pickers become new social actors of a productive chain of recycling material, but the study also demonstrates that the construction of citizenship is still unstable as the fundamental rights of waste pickers are still not provided.
\end{abstract}

Keywords: Waste pickers. Citizenship. Social representations.

"Doutora e Mestre em Comunicação pela Universidade do Vale do Rio dos Sinos (Unisinos). Professora adjunta no Programa de Pós Graduação Ambiente e Desenvolvimento (PPGAD) e dos cursos de Comunicação Social na Univates, Lajeado, Rio Grande do Sul, Brasil. E-mail: janemazzarino@univates.br

"Mestre em Ciência Política, Socióloga (UFRGS), professora da área de Humanidades do Centro Universitário Univates. E-mail: shirleis@cpovo.net 


\section{Introdução}

O ambientalismo surge como tema analítico nas Ciências Sociais a partir dos anos 70 e, gradativamente, busca um lugar próprio no pensamento acadêmico, principalmente nos estudos referentes à Sociologia Ambiental. Assim, temas como a questão dos resíduos sólidos tornaram-se objetos de investigação sociológica com a análise das políticas públicas, da precarização das relações de trabalho, da exclusão social de catadores/papeleiros/ carroceiros, dentre outros ${ }^{1}$.

Desde meados da década de 80 , os catadores e separadores de resíduos sólidos têm se articulado de Norte a Sul do Brasil, formando redes que, mesmo incipientes, divulgam essa alternativa informal e precária de renda para as pessoas excluídas do direito ao trabalho e às condições primordiais de sobrevivência, moradia, educação e saúde. Em diferentes regiões do país, caracterizadas por diversas realidades socioculturais, a sobrevivência a partir da separação dos resíduos sólidos passou a ser uma necessidade. Atualmente, os grupos mais organizados percebem que, além de coletar e separar os materiais recicláveis, precisam conhecer o processo de reciclagem e comercialização, objetivando maior autonomia e melhores rendimentos. No entanto, essa percepção não está disseminada.

Este artigo analisa a relação dos catadores com seu universo de trabalho, a fim de compreender quais possibilidades de inclusão e construção da cidadania podem ser vislumbradas, levando-se em conta a tradição sociopolítica do Estado. Realizouse um estudo comparativo entre catadores/ papeleiros de Estrela/RS, divididos em dois grupos: os catadores que atuam na Unidade de Triagem (UTL) e catadores de rua que atuam individualmente. Os dois grupos são alvos da política pública Brasil Joga Limpo, implantada pela Prefeitura Municipal por meio de recursos federais. A metodologia utilizada é qualitativa, baseada na pesquisa bibliográfica e documental, observação e entrevistas semiestruturadas. As narrativas das entrevistas foram tratadas por meio da análise de conteúdo temática.

\footnotetext{
1 Optamos por manter a diversidade de termos com que esse grupo social é identificado em diferentes contextos.
}

Analisou-se o contexto sócio-históricopolítico nacional, as recentes transformações resultantes do processo de globalização e suas consequências, e as contradições relacionadas à construção da cidadania no Brasil, para então focar-se o cenário em que se inserem os catadores.

Os catadores de resíduos constituem-se em uma categoria de trabalhadores que, no Brasil, atuam individualmente (mercado informal), em cooperativas ou como funcionários públicos (formal). Trata-se de um grupo de profissionais que cresce a cada dia no Brasil e no mundo, tanto em pequenos municípios quanto em metrópoles, como aponta o estudo de Mazzarino (2013).

\section{Da tradição patriarcal ao ambientalismo}

Os clássicos estudos da sociologia sobre a sociedade brasileira (HOLANDA, 1984; FREYRE, 2004) registram o domínio da tradição patriarcal assentada em uma estrutura colonial de raízes rurais, comandada por fazendeiros escravocratas. O latifúndio, a casa-grande e a senzala seriam as marcas dessa sociedade colonial.

Migueles (2007) cita as lealdades pessoais como traços característicos da cultura brasileira, alegando que os fundamentos das relações econômicas estariam minados pelo personalismo, originando o tipo de dominação patriarcal e patrimonialista que se caracteriza pela apropriação privada do patrimônio público. Daí resultaria uma sociedade verticalizada e excludente, com frágeis mecanismos institucionais e um Estado atrelado às elites econômicas. Essas características perduram no Estado Moderno.

A modernização da sociedade brasileira, iniciada ainda nos anos 30, no governo de Getúlio Vargas, imprimiu um ritmo acelerado ao processo de urbanização do país, que foi seguido pela política desenvolvimentista do governo de Juscelino Kubitschek, nos anos 50. Aurbanização teve o seu ápice com o projeto político-econômico dos governos militares, quando, a partir do golpe de 1964, o Brasil ruma em direção a um novo modelo de desenvolvimento, com a instalação de um moderno parque industrial no centro-sul do país.

O regime autoritário no Brasil governou por meio de atos institucionais, extinguindo o pluripartidarismo e adotando práticas de censura 
e de tortura típicas dos regimes de força, que geraram um quadro de apatia social. Os militares brasileiros construíram o "milagre econômico"2, em meados da década de 70 . Até aquele momento "[...] as classes trabalhadoras foram vistas completamente subjugadas pela lógica do capital e pela dominação de um Estado onipotente." (SADER, 1988, p. 34). Mas, no final da década emergiram movimentos sociais contestadores do regime militar, tomando como eixo a matriz sindical que despontava com a organização do movimento operário no $\mathrm{ABC}$ paulista ${ }^{3}$. Esse é o cenário histórico e político em que se organiza o movimento ambiental no Brasil.

Os primeiros grupos ambientalistas surgem no país na segunda metade da década de 70, nas regiões Sul e Sudeste. Seu objetivo é denunciar os principais problemas de degradação ambiental nas cidades. São formados por poucos ativistas e carecem de apoio financeiro. O movimento ecológico da época constitui-se de movimentos paralelos e independentes: comunidades alternativas rurais e movimentos de denúncia da degradação ambiental urbana. $\mathrm{Na}$ primeira metade da década de 80 proliferam-se os grupos ambientalistas, muitos deles com vida curta, emergindo em torno de temas de luta específicos e com pouca estrutura organizativa (VIOLA, 1992). ${ }^{4}$

Duas questões atreladas foram importantes para o ambientalismo dos países em desenvolvimento: a justiça social e o desenvolvimento econômico. Assim, em 1986 os ambientalistas descobrem que a conexão com os setores populares é primordial para pensar soluções para a problemática ambiental atrelada à problemá-

\footnotetext{
2 Assim ficou conhecido o período de crescimento econômico dos governos militares até 1974. "Milagre" baseado em uma política de contenção salarial e no pacto empresariado-governo, que excluiu os trabalhadores da divisão de riquezas, o que fez com que o descontentamento quanto à questão salarial se generalizasse.

3 O ABC paulista é como se denomina a região industrial do estado de São Paulo, formada pelos municípios de Santo André, São Bernardo do Campo e São Caetano. Essa região abrigou os grandes parques da indústria automobilística na década de 70 .

${ }^{4}$ Segundo Viola, havia no Brasil aproximadamente 40 grupos ambientalistas em 1980, localizados, principalmente, nas regiões Sul e Sudeste. Em 1985, o número de grupos ambientalistas tinha chegado a aproximadamente 400 , os quais tinham pelo menos um ano de existência.
}

tica social. Esse momento constitui-se como a gênese de projetos como o da organização dos separadores/catadores de resíduos sólidos domésticos (MAZZARINO, 2013).

É na década de 90 que se firma a necessidade de pensar as relações entre desenvolvimento econômico e proteção ambiental, questão que afeta os setores ambientalistas, mas vai além deles, atingindo a sociedade e o Estado brasileiro de modo geral. A sustentabilidade ambiental adquiriu legitimidade a partir da Rio 92, evento que fez emergir e legitimou o papel da sociedade civil de todo planeta na busca de soluções para a crise socioambiental global (VIOLA, 1987).

Leis (1995) trabalha com a hipótese de que o ambientalismo constitui um amplo movimento histórico de alcance global e importância prática no processo de redefinição do caráter da política mundial, um paradigma emergente, com capacidade explicativa e transformadora da realidade social e política. O movimento ambientalista propõe um sistema de valores sustentado no equilíbrio ecológico, que se refere à justiça social, à não violência ativa e à solidariedade com as gerações futuras.

Esses novos valores apontam para uma sociedade que se diferencia dos valores tanto da sociedade patriarcal (verticalizada, escravocrata, elitizada) quanto da Modernidade (industrializada, desenvolvimentista, individualista, capitalista), mas não rompem totalmente com eles, apesar da maior flexibilidade, volatilidade e fragmentação.

A dialética local-global surge impondo a necessidade de cada um tornar-se cidadão do mundo e romper com as identidades fixas (marcas da sociedade patriarcal e da Modernidade), desterritorializar-se e pensar novas formas de cidadania. Nesse contexto, a cidadania ambiental surge como uma nova faceta de análise e de comportamento sociopolítico. Mas, qual cidadania emerge nesse contexto de profundas desigualdades sociais vivenciadas pelos catadores? Para dar conta dessa questão, é necessário retomar alguns aspectos fundamentais sobre 0 conceito de cidadania. 


\section{Cidadania e trabalho na sociedade global}

No Brasil, a Constituição Federal de 1988 representou um marco no recente processo de democratização, evidenciando a presença de uma matriz progressista que efetiva a democracia formal. Permanecem, entretanto, as dificuldades quanto à implementação sobre direitos e deveres dos cidadãos. As discussões iniciais sobre os direitos são baseadas em valores que remetem às revoluções liberais do século XVIII, cujos marcos são a Revolução Francesa, a Revolução Inglesa e a Revolução Americana. No Brasil, é somente após a Proclamação da República e o fim da escravidão que, gradativamente, essa discussão toma conta do espaço público. Após diversas lutas sociais, no campo e na cidade, chegamos ao século $X X$ falando de "novos atores sociais", de "novos direitos", de "novas formas associativistas". Tudo isso em função das mudanças constantes evidenciadas no cenário político brasileiro com a democratização iniciada na década de 80. Paralelamente, no cenário econômico, a globalização e seus reflexos atingem o mundo do trabalho gerando novas transformações sociais, dentre as quais está a mundialização da pobreza e dos trabalhadores precários. Nascimento (2003, p. 36) afirma que:

[...] sempre houve um certo elo orgânico entre os mundos da riqueza e da pobreza [...] Mas os tempos atuais estão mostrando uma nova realidade: a separação, pela crise do mundo do trabalho, entre os mundos da riqueza e da pobreza que se vai tornando excluída (grifos do autor).

Segundo o mesmo autor, as mutações recentes no espaço social estão relacionadas à crise do mundo do trabalho, a qual se deve às rápidas transformações tecnológicas e à globalização da produção de bens, com a exploração da mão-de-obra barata no mercado mundial. Como consequência, a desqualificação, o desemprego, a precarização das relações sociais, as crescentes mutações do mercado de trabalho assinalam para uma nova diretiva do século XXI. Isso representa um enorme desafio aos governos atuais. E, como as políticas públicas podem reverter esse quadro social?

Ao mesmo tempo em que se alcança a igualdade jurídico-política com a Constituição de 1988, observa-se no Brasil a ampliação das desigualdades sociais, caracterizada pelo aumento da pobreza e da exclusão, que determinam novas facetas no mundo do trabalho, com trabalhadores qualificados desempregados e aqueles com menos qualificação sendo cada vez mais excluídos, chegando-se a se discutir se ainda gozariam da condição de "cidadãos".

Segundo a clássica definição de Marshall (1967), criada a partir do contexto inglês, a cidadania constitui-se com a efetivação dos direitos civis, políticos e sociais. Os direitos civis embasam a concepção liberal clássica e, juntamente com os direitos políticos (individuais), são denominados direitos de primeira geração. Já os direitos sociais seriam os direitos de segunda geração. Essa classificação se adequou à realidade inglesa, mas não se aplica totalmente ao contexto brasileiro, já que o conceito de Marshall se situa historicamente e não dá conta da realidade do mundo globalizado contemporâneo, quando os diferentes direitos não são usufruídos de forma sucessiva e pontual. O direito ao meio ambiente saudável, por exemplo, trata-se de um direito difuso, considerado de terceira geração ou novo tipo de direito, pois não se enquadra especificamente como direito civil, político ou social, mas engloba todos eles (BOBBIO, 2000).

A referência para a cidadania é a ideia de uma igualdade de status, segundo Marshall(1967). O autor não problematiza as desigualdades econômicas, e sim as desigualdades relativas ao mundo cívico. Como as democracias modernas têm mundos cívicos diferentes, deve-se ter claro que o cidadão brasileiro é diferente do cidadão inglês ou francês de séculos passados. Para isso, é necessário contextualizar a discussão da cidadania no Brasil, onde a tradição autoritária, excludente e patrimonialista da cultura política brasileira fez com que o Estado incorporasse a cultura republicana, influenciada pelos ideais burgueses e os ideais do Estado democrático liberal, em detrimento do Estado democrático social. As políticas do Estado de Bem-Estar Social (Welfare State) no Brasil foram barradas por interesses de uma elite interessada na concentração, e não na divisão de riquezas. Como pensar em etapas de constituição de direitos do homem em um país com configuração política que expõe desigualdades sociais gritantes? 
Nascimento (2003, p. 68) refere-se à "nova" exclusão social construída por um processo múltiplo de expulsão do mundo do trabalho, de negação de direitos e de ruptura de vínculos societários e comunitários. Sem direitos sociais assegurados, os "novos" excluídos têm seu espaço político e civil restringido. Esse quadro de exclusão e marginalidade se reflete em diferentes cidades do Brasil e do mundo, evidenciando o que consideramos ser a localização da pobreza globalizada devido às transformações sociais já abordadas.

A economia global modificou o mercado de trabalho, as tradições e as instituições. Os costumes das culturas locais que fomentavam vínculos comunitários e de pertencimento se modificam. Os sem emprego, sem instrução e sem qualificação sobrevivem como pedintes ou, na tentativa de viver dignamente, muitos assumem a atividade da catação para garantir sua sobrevivência, em meio a uma outra multidão, com instrução, com qualificação. A aproximação entre Mercado e Estado acaba gerando o distanciamento dos cidadãos da esfera política e econômica e, dessa forma, não se garantem os direitos pressupostos para a cidadania (liberdade, participação, bem-estar social, direitos de terceira e até quarta geração). Nesse contexto surgem, embrionariamente, algumas experiências alternativas que indicam a possibilidade de reinserção social de alguns grupos, a partir da catação/triagem de resíduos sólidos, uma vez que o lixo produzido pela sociedade de consumo também se transforma em mercadoria.

O lixo ou os resíduos são, no entanto, uma mercadoria de baixo valor enquanto matéria-prima, o que dá razão a Verdum (2000, p. 188) de afirmar que "[...] as pessoas que exercem a atividade de coleta de papel situam-se nos níveis mais baixos da hierarquia socioeconômica urbana, provindas de outras atividades econômicas que, pela própria dinâmica da economia nacional, vem sendo desaquecidas". O autor menciona, por exemplo, o "ciclo do papel", que inicia com o usuário em geral, passando pelo papeleiro, pelo depósito de aparas e chega, finalmente, à indústria processadora de papéis. Pode-se estender essa divisão à coleta, triagem, armazenamento e venda de outros materiais recicláveis, como o vidro, o plástico, o metal. O papel do catador de qualquer desses tipos de resíduos, no processo, é também "residual" hierarquicamente, mesmo levando-se em conta que o mercado da "sucata" cresce vertiginosamente com a sociedade caracterizada pelo consumo e descartes imediatos ${ }^{5}$.

Verdum (2000, p. 197) alerta sobre os fatores geradores da situação socioeconômica desse grupo social, que evidenciam não somente o êxodo rural, mas também "[...] o processo de urbanização atrelado a um sistema econômico incapaz de oferecer empregos regulares, gerando a deterioração dos salários e, ainda, a marginalização destes trabalhadores". Essa situação é ampliada pela existência de uma "cadeia" de intermediários, os "picaretas" e os "aparistas", que, segundo o autor, seriam os "banqueiros" do sistema. Forma-se assim uma rede de marginalidade e exclusão social que, contraditoriamente, coloca-se como uma forma, mesmo que precária, de inclusão no mercado de trabalho.

Essa realidade, que se torna mais visível nas grandes cidades a partir da década de 90, amplia-se cada vez mais para os pequenos municípios. O trabalho cotidiano de catar, separar e encaminhar os resíduos para a reciclagem, diminuindo o volume destinado aos aterros e lixões, torna-se um trabalho de crescente importância social e ambiental no contexto do mundo globalizado. A questão que se coloca é, se as representações sociais dos catadores sobre seu trabalho estão sendo relacionadas com a problemática ambiental, como podem, dessa forma, estar apontando para a construção da cidadania ambiental?

Afinal, a multiplicação dos catadores e a emergência do discurso da cidadania ambiental são movimentos que surgem paralelamente na década de 90, com as transformações do mundo globalizado. A cidadania ambiental representa,

\footnotetext{
${ }^{5} \mathrm{O}$ sucateiro é denominado de várias formas: papeleiro, reciclador, carroceiro, catador. Em uma tentativa de classificação, Sosniski (2006, p. 7-8) denomina como reciclador o trabalhador das unidades de triagem que possui características específicas quanto ao seu trabalho, uma vez que executa suas tarefas em um local específico, em grupo, com maquinaria e uma técnica corporal que Ihe é peculiar, além de receber treinamento e cursos do poder público. Já o carroceiro se utiliza da carroça, percorre diversos pontos de coleta, usando, além de seu corpo, o veículo de tração animal para o transporte da coleta diária de material. O catador normalmente exerce seu trabalho em sua própria residência, sendo seu corpo o único instrumento de trabalho. Nas ruas das cidades esses três perfis de trabalhadores precários se misturam.
} 
hoje, uma nova discussão sobre os direitos, atrelada à justiça social e ao desenvolvimento econômico pensado a partir da ótica da sustentabilidade. Segundo Loureiro (2002), a cidadania se constrói permanentemente, já que se constitui ao dar significado ao pertencimento do indivíduo a uma sociedade, em cada fase histórica. Está relacionada à participação do indivíduo em organizações sociais que formam a sociedade civil nacional e internacional, que tenham poder deliberativo. Dessa forma, a cidadania vem incorporando direitos e sentidos diversos ao longo do tempo, relacionados a mudanças sociais históricas, caso do fenômeno da globalização - expressão do desenvolvimento capitalista sem fronteiras, devido à evolução dos meios de comunicação, informação e de transporte. Para Loureiro (2002, p.76),

A eco-cidadania ou cidadania planetária é um conceito utilizado para expressar a inserção da ética ecológica e seus desdobramentos no cotidiano, em um contexto que possibilita a tomada de consciência individual e coletiva das responsabilidades tanto locais e comunitárias quanto globais, tendo como eixo central o respeito à vida e a defesa do direito a esta em um mundo sem fronteiras geopolíticas. Nesse conceito, amplia-se o destaque ao pertencimento à humanidade e a um planeta único.

Enquanto Loureiro (2002) entende que a globalização fragiliza o exercício local da cidadania, Santos (2003) chama a atenção para experiências em que a globalização fortalece os movimentos de cidadania planetária, por meio da organização de redes sociais, também sem fronteiras, irmanadas na luta por direitos da mesma natureza, considerados de terceira geração: sexuais, ambientais, humanos etc.

A relação entre cidadania e temas de cunho ambiental, segundo Castro e Baeta (2002), remete a questões que vão além das dimensões presentes na concepção de cidadania clássica (direitos civis, políticos e sociais) e referem-se à responsabilidade social em relação à natureza e ao senso de pertencimento global. A autonomia do indivíduo exige a crescente construção de significados e as possíveis inter-relações entre instâncias sociais, econômicas, políticas públicas e qualidade de vida, as quais estão relacionadas com os direitos ambientais.
Gutiérrez e Prado (1999) afirmam que os novos agentes da cidadania ambiental da sociedade planetária devem preocupar-se em desenvolver a capacidade de compreender e recriar o novo contexto socioambiental pelo conhecimento de suas causas e consequências; a capacidade de relacionar a ecologia do eu com as exigências da nova cidadania ambiental; e a capacidade de sentir e expressar a vida e a realidade tal e como deve ser sentida e vivida, não excluindo a subjetividade, a emoção e o sentimento.

Esses diferentes aspectos relacionados ao conceito de cidadania ambiental, conforme apontados pelos autores, são investigados neste artigo a partir das representações construídas por esses atores sociais sobre seu trabalho e sobre temas ambientais. O objetivo é compreender quais possibilidades de inclusão e construção da cidadania podem ser vislumbradas, levando-se em conta a tradição sociopolítica do Estado. Para isso, realizou-se um estudo comparativo de dois grupos de catadores de Estrela, município do Vale do Taquari, RS.

\section{Método}

Nesta pesquisa foram utilizadas, predominantemente, metodologias qualitativas que incluíram a pesquisa bibliográfica e documental, observação, entrevistas semiestruturadas e análise de conteúdo. Trata-se de um estudo exploratório e que não requer que sejam feitas generalizações sobre a realidade estudada. No total, foram entrevistados 21 trabalhadores: sete que trabalham na Unidade de Tratamento de Lixo (UTL), onde funciona a central de triagem do município, e 14 catadores que atuam individualmente, sendo estes moradores dos bairros Marmitt, Moinhos e Imigrantes, locais que reúnem grande número de catadores.

A amostra é do tipo não probabilística (os sujeitos são escolhidos por determinado critério) e intencional, sendo os catadores escolhidos por acessibilidade. Segundo Vergara (2004, p.51), os informantes podem ser selecionados por acessibilidade e/ou por tipicidade: "Por acessibilidade: longe de qualquer procedimento estatístico, seleciona elementos por facilidade de acesso a eles" e "[...] por tipicidade: constituída pela seleção de elementos que o pesquisador considere representativos da população-alvo, o que requer profundo conhecimento dessa população". 
As entrevistas foram transcritas integralmente. Depois, em paralelo, foram organizadas as respostas dos diferentes indivíduos de cada grupo para as mesmas perguntas. Sobre as narrativas coletadas procedeu-se a análise de conteúdo qualitativa e temática.

\section{Representações sobre trabalho e ambiente: qual cidadania?}

O município de Estrela localiza-se no Vale do Taquari, região Centro-leste do Rio Grande do Sul, estado mais ao Sul do Brasil. Conforme dados da Fundação de Economia e Estatística (FEE, 2007) $)^{6}$, a população do Vale do Taquari, em 2007, era de 316.325 habitantes. A FEE (2006) aponta que o Índice de Desenvolvimento Socioeconômico (IDESE) médio da região é de $0,73^{7}$. Estrela ocupa a $29^{a}$ posição no ranking do Idese. Trata-se de um dos municípios mais antigos da região, colonizado por imigrantes alemães e distante $113 \mathrm{~km}$ de Porto Alegre, capital do estado. Conforme dados do IBGE (2007), a cidade possui área geográfica de $184 \mathrm{~km}^{2} \mathrm{e}$ população total de 29.071 habitantes, dos quais $86,6 \%$ vivem na área urbana. Sua economia é baseada, principalmente, na indústria, seguida do comércio e do setor primário.

A Secretaria Municipal do Meio Ambiente e Saneamento Básico (SMMASB) é a responsável pela coleta e destino final dos resíduos sólidos domésticos em Estrela. A legislação que regulamenta as questões sobre os resíduos sólidos urbanos é o Código Municipal do Meio Ambiente, instituído pela Lei $n^{\circ} 3.294 / 99$. Segundo dados dessa Secretaria, a quantidade média de lixo recolhida no município é de 450 toneladas/mês, dos quais 105 toneladas/mês são oriundas da zona rural. O município mantém o sistema de

\footnotetext{
6 FUNDAÇÃO DE ECONOMIA E ESTATÍSTICA. Índice de desenvolvimento socioeconômico. 2007. Disponível em: <http:// www.fee.tche.br/sitefee/pt/content/estatisticas/pg_idese php?ano=2005>. Acesso em: 18 jul. 2008.

7 Segundo a FEE (2008), "o Idese (Índice de Desenvolvimento Socioeconômico) é um índice sintético, inspirado no IDH, que abrange um conjunto amplo de indicadores sociais e econômicos classificados em quatro blocos temáticos: Educação; Renda; Saneamento e Domicílios; e Saúde. [...] O Idese varia de zero a um e, assim como o IDH, permite que se classifique o estado, os municípios ou os Coredes em três níveis de desenvolvimento: baixo (índices até 0,499 ), médio (entre 0,500 e 0,799 ) ou alto (maiores ou iguais que sic 0,800$)$ ".
}

coleta seletiva em todos os bairros urbanos e na área rural. Esses resíduos são destinados à Usina de Tratamento de Lixo Doméstico (UTL).

A SMMASB desenvolve um projeto com catadores vinculados à UTL denominado Programa Brasil Joga Limpo, iniciado em parceria com o governo federal no ano de 2001, quando era mantido com recursos do Fundo Nacional de Meio Ambiente (FNMA), repassados pela Caixa Econômica Federal. A partir de 2003 a Prefeitura de Estrela passou a administrar o Programa. Até 2004 o projeto foi pensado visando a organização de uma cooperativa de catadores, mas, conforme entrevista com a assistente social, o forte individualismo entre os mesmos impossibilitou o projeto. Levantamento realizado pela Prefeitura Municipal, em 2007, aponta a existência de 142 catadores no município.

Optou-se por comparar a realidade vivida pelos catadores que atuam na UTL e aqueles que atuam individualmente nas ruas do município a fim de compreender se diferentes relações com o universo de catação estão determinando diferentes construções de sentidos ambientais e laborais. Os dois grupos são enquadrados como catadores, profissão reconhecida pelo Ministério do Trabalho e Emprego na Classificação Brasileira de Ocupações em $2002^{\circ}$. A seguir são descritos e analisados os dados de cada grupo separadamente, para depois os dados serem comparados.

\section{Catadores que atuam na UTL}

Na UTL os catadores são admitidos como "operários", selecionados via concurso, com todos os direitos trabalhistas assegurados. Esses catadores são gerenciados por um químico contratado pela administração municipal. Nenhum dos entrevistados concluiu o ensino fundamental, e dois recebem Bolsa Família programa social do governo federal.

\footnotetext{
8 Conforme o documento, a categoria é caracterizada como: "Títulos 5192 - 05 Catador de material reciclável - Catador de ferrovelho, Catador de papel e papelão, Catador de sucata, Catador de vasilhame, Enfardador de sucata (cooperativa), Separador de sucata (cooperativa), Triador de sucata (cooperativa). Catadores de material reciclável - Descrição sumária - Catam, selecionam e vendem materiais recicláveis como papel, papelão e vidro, bem como materiais ferrosos e não ferrosos e outros materiais reaproveitáveis. Formação e experiência - $\mathrm{O}$ acesso ao trabalho é livre, sem exigência de escolaridade ou formação profissional".
} 
Observou-se que o relacionamento entre os operários da Unidade aparentemente é bastante amistoso. As reuniões são momentos esperados, e a maioria participa ativamente da avaliação do processo de trabalho. A assistente social, responsável pelas reuniões, possui um horário fixo de visitação à UTL, com reuniões pré-agendadas.

Algumas falas dos operários denotaram uma posição de não protagonismo e baixa autoestima, ao mesmo tempo que demonstram um sentimento de identificação social com o grupo técnico envolvido na organização do processo de trabalho. Os informantes afirmam que o relacionamento na UTL é de ótimo a bom, incluindo a relação com o gerente. $O$ discurso da coordenação do projeto também salienta a efetivação de laços solidários e de coesão entre os operários.

Pode-se afirmar que esse grupo tem garantido o direito ao trabalho e, com isso, o acesso aos serviços essenciais do município, com os encaminhamentos feitos pela Secretaria Municipal de Meio Ambiente e Assistência Social. Entretanto, as falas desse grupo explicitam o sentimento de preconceito que observam na sociedade em relação ao trabalho que exercem e o desrespeito dos moradores que "não separam corretamente os resíduos". Isso pode estar relacionado a um distanciamento dos mesmos em relação à comunidade, pois esses catadores não mantêm relações diretas com a população local. Assim, surgem indicativos de que o grupo apresenta sentimento de exclusão em relação à sua atividade profissional.

Quando questionados sobre o Programa Brasil Joga Limpo (ao qual estão vinculados), apenas dois respondentes afirmaram saber do que se trata. Isso indica lapsos do discurso da chefia entre os atores envolvidos, uma vez que a coordenadora do projeto mantém reuniões semanais com os operários da UTL, e cinco deles não identificaram a ligação entre as reuniões e a política pública. O mesmo acontece em relação ao Fórum Lixo e Cidadania, evento que também faz parte do Programa Brasil Joga Limpo. Apenas dois respondentes mostraram-se informados a respeito. Esse desconhecimento está relacionado com o fato de o Fórum ter tido seu público-alvo desviado dos catadores para os escolares ${ }^{9}$.

Os sete entrevistados afirmam que reaproveitam resíduos como panelas de pressão, isqueiros, telefones celulares, roupas, brinquedos, calçados, roupas de cama, pratos, copos, talheres, potes, tênis. Todos afirmam reutilizar resíduos orgânicos em hortas, tratando-os por meio da compostagem.

\section{Catadores individuais que atuam nas ruas}

Além dos operários da UTL, também foram entrevistados catadores informais residentes na Vila Marmitt, no bairro Moinhos e no bairro Imigrantes, totalizando 14 entrevistas, que foram realizadas nas casas de cada um. É importante destacar que eles apresentaram dificuldades em responder a determinadas questões. Esse fato pode estar relacionado com a baixa escolaridade dos respondentes (dos entrevistados, apenas dois menores estão na sétima série do ensino básico). O perfil socioeconômico dos entrevistados aponta que nenhum deles concluiu o ensino fundamental. Seis deles recebem assistência via Bolsa Família, Bolsa Escola ou auxílio em caso de doença - todos programas de assistência.

O tempo que trabalham com catação varia de um mês a 20 anos. A maioria afirma ganhar em torno de 300 reais mensais, havendo outros familiares que ajudam no trabalho (filhos, marido, mãe, mulher, irmã, tio). Esse trabalho familiar é uma característica recorrente nessa categoria.

Percebeu-se o sentimento de discriminação e isolamento devido à ausência do Estado na efetividade dos direitos sociais. Antes de ser catador, um deles afirmou que, quando observava os catadores, "eu pensava como os outros pensam de nós agora. Eu achava que ser catador era feio. Depois eu vi que não era assim,

\footnotetext{
9 Entre as atividades gerais do Programa Brasil Joga Limpo está a realização de visitas mensais às residências dos catadores, trabalhos de grupo com os funcionários da UTL e realização do Fórum Lixo e Cidadania, tratando sobre temas de meio ambiente desenvolvidos para a comunidade. Além das atividades com os catadores, a comunidade é contemplada com ações de sensibilização para adotar a coleta seletiva por meio da Sala Verde Manoel Ribeiro Pontes Filho, projeto que funciona na Secretaria do Meio Ambiente. Atualmente, as escolas são os principais atores que desenvolvem atividades de educação ambiental, incluindo visitas dos alunos e professores à UTL.
} 
que é o dinheiro que tá na rua". Dessa frase depreendem-se duas observações: a representação de que o outro o vê com preconceito e a necessidade de sobrevivência, que se sobrepõe à visão desse outro que consideraria o trabalho da catação indigno (o "feio" torna-se menos feio, pois garante a sobrevivência).

Esse grupo é excluído do acesso ao trabaIho formal, que não Ihes foi garantido pelo Estado, ao contrário dos catadores inseridos no contexto da UTL. Outra inversão que as falas apontam refere-se à interação com a comunidade. Enquanto os catadores da UTL sentem-se vítimas do preconceito da comunidade e mantêm uma relação indireta com ela, os catadores individuais sentem-se parte da comunidade, o que pode estar relacionado ao fato de terem uma relação direta com os moradores. Mesmo que algumas falas indiquem a existência de um certo desrespeito, outras observam que há apoio e simpatia dos moradores em relação ao trabalho dos catadores.

Com relação aos resíduos que eles aproveitam, foram citados: liquidificadores, máquinas de lavar, ventiladores, centrífugas, roupas, armários, tapetes, panelas, pratos, baldes, lápis, borrachas, verduras. Observa-se que são materiais diferentes dos citados pelos operários da UTL, já que incluem entre os resíduos que reutilizam os do tipo tecnológico e alimentos, os quais não chegam à UTL porque são recolhidos antes pelos catadores individuais.

Os quadros a seguir (1 e 2) mostram uma síntese comparativa das práticas ambientais e práticas de trabalho entre operários da UTL e catadores individuais de Estrela/RS:

Quadro 1. Representações sobre trabalho

\begin{tabular}{|c|c|c|}
\hline Questões analisadas & $\begin{array}{l}\text { Operários da UTL } \\
\text { (7 entrevistados) }\end{array}$ & $\begin{array}{l}\text { Catadores de rua } \\
\text { (14 entrevistados) }\end{array}$ \\
\hline Visão sobre seu trabalho & $\begin{array}{l}\text { A maioria gosta do que faz. Sentem } \\
\text { satisfação com o que fazem }\end{array}$ & $\begin{array}{l}\text { A maioria gosta do que faz. O } \\
\text { trabalho é considerado bom, honesto, } \\
\text { ajuda a limpar. Mistura de orgulho por } \\
\text { sobreviver do seu trabalho, prazer de } \\
\text { trabalhar, mas, alguns confessaram } \\
\text { terem vergonha de catar }\end{array}$ \\
\hline Como definem sua profissão & Operário, reciclador & Reciclador, charreteiro, papeleiro \\
\hline Reconhecimento da profissão & Todos desconhecem & Todos desconhecem \\
\hline Dificuldades no trabalho & $\begin{array}{l}\text { Desrespeito de pessoas da } \\
\text { comunidade que misturam de lixo } \\
\text { reciclável e orgânico: envio de } \\
\text { bichos mortos ao aterro; problemas } \\
\text { com a esteira da triagem; vidros mal } \\
\text { armazenados nos sacos de lixo; } \\
\text { pouco engajamento da população } \\
\text { na coleta seletiva }\end{array}$ & $\begin{array}{l}\text { Abandono social, concorrência, } \\
\text { desrespeito dos gestores ambientais, } \\
\text { discriminação, riscos de doenças, } \\
\text { chuva, falta de equipamentos, } \\
\text { preconceito, falta de local para } \\
\text { triagem dos resíduos }\end{array}$ \\
\hline Visão da comunidade & $\begin{array}{l}\text { Preconceito: acham que é trabalho } \\
\text { sujo; são considerados lixeiros. } \\
\text { Porém, alguns elogiam o trabalho }\end{array}$ & $\begin{array}{c}\text { Sentem-se aceitos, mantêm } \\
\text { boas relações sociais, sentem-se } \\
\text { injustiçados quando são confundidos } \\
\text { com os catadores que deixam lixo } \\
\text { esparramado após a coleta nas lixeiras. } \\
\text { Mantêm boas relações com outros } \\
\text { catadores. Não observam conflitos com } \\
\text { a política de coleta seletiva }\end{array}$ \\
\hline Direitos trabalhistas & $\begin{array}{c}\text { Garantidos por meio de carteira } \\
\text { assinada }\end{array}$ & Não estão garantidos \\
\hline Direitos sociais & Acesso facilitado & Acesso dificultado \\
\hline
\end{tabular}

Fonte e organização: os autores 
Quadro 2. Representações sobre ambiente

\begin{tabular}{|c|c|c|}
\hline Questões analisadas & $\begin{array}{c}\text { Operários da UTL } \\
\text { (7 entrevistados) }\end{array}$ & $\begin{array}{c}\text { Catadores de rua } \\
\text { (14 entrevistados) }\end{array}$ \\
\hline $\begin{array}{c}\text { Relação trabalho/meio } \\
\text { ambiente }\end{array}$ & $\begin{array}{c}\text { Todos percebem relações, já que } \\
\text { evitam a poluição da natureza e } \\
\text { reciclam materiais, diminuindo a } \\
\text { demanda de recursos naturais }\end{array}$ & $\begin{array}{c}\text { Apenas cinco entrevistados } \\
\text { percebem relações }\end{array}$ \\
\hline $\begin{array}{c}\text { Concepção de meio } \\
\text { ambiente }\end{array}$ & $\begin{array}{c}\text { Cuidar do meio ambiente, cuidados } \\
\text { com o lixo, limpeza, árvores, } \\
\text { natureza }\end{array}$ & $\begin{array}{c}\text { Limpeza, capricho, não jogar lixo em } \\
\text { locais inadequados, organização, } \\
\text { preservar a natureza, mata, árvores }\end{array}$ \\
\hline $\begin{array}{c}\text { Influência do trabalho na } \\
\text { relação com o meio ambi- } \\
\text { ente }\end{array}$ & $\begin{array}{c}\text { O trabalho mudou a relação } \\
\text { com o meio ambiente: separam } \\
\text { e reaproveitam mais, fazem } \\
\text { compostagem }\end{array}$ & $\begin{array}{c}\text { Reaproveitam materiais; alguns } \\
\text { fazem compostagem }\end{array}$ \\
\hline $\begin{array}{c}\text { Conscientização das pes- } \\
\text { soas sobre coleta seletiva }\end{array}$ & $\begin{array}{c}\text { Deve melhorar, já que alguns } \\
\text { participam e outros não. Porém, } \\
\text { eles mesmos confundiram os dias } \\
\text { de recolhimento do lixo reciclável }\end{array}$ & $\begin{array}{c}\text { Deve melhorar. A comunidade } \\
\text { desperdiça muito. Alguns participam } \\
\text { da coleta seletiva e outros não }\end{array}$ \\
\hline Problemas regionais & $\begin{array}{c}\text { Lixo, aquecimento global, efluentes } \\
\text { industriais no Rio Taquari }\end{array}$ & $\begin{array}{c}\text { Colocar fogo no lixo; atirar lixo e } \\
\text { animais mortos nos bueiros e no } \\
\text { mato; poluição do banhado do bairro } \\
\text { onde alguns vivem; desmatamento }\end{array}$ \\
\hline
\end{tabular}

Fonte e organização: os autores

\section{Discussões}

Os dados apontam que os operários da UTL, já integrados ao processo de trabalho formal, com carteira assinada e vínculo empregatício, apresentam maior clareza nas respostas fornecidas nas entrevistas, e, embora com raras evidências, um maior discernimento de seu papel como cidadãos e como agentes ambientais. Dos 14 catadores individuais, cinco percebem a relação do seu trabalho com o meio ambiente. Os outros não responderam à pergunta, demonstrando não tê-la compreendido, o que consideramos referir-se à inadequação das questões das entrevistas ao público a que se destinavam.

A melhor compreensão das perguntas pelos operários da UTL deve ser analisada levando-se em conta o contexto vivenciado por esse grupo, que tem semanalmente reuniões com a assistente social, coordenadora do Programa Brasil Joga Limpo. Com isso, esses operários têm a oportunidade de refletir conjuntamente sobre questões coletivas referentes ao seu processo de trabalho, envolvendo a questão ambiental. No entanto, a maioria dos catadores, tanto da UTL como os catadores individuais, desconhece o Programa Brasil Joga
Limpo e o Fórum Lixo e Cidadania, que é parte do Programa e voltado para discussão pública sobre a problemática dos resíduos, tendo como público prioritário os catadores.

Os dois grupos desconhecem a regulamentação da profissão, o que indica a fragilidade dos vínculos comunitários. Essa fragilidade encontra eco na dificuldade de formação de uma cooperativa de catadores pelo poder público municipal, que era um dos objetivos da implantação da política pública.

Os dois grupos compartilham um gostar do que fazem, apesar de alguns entrevistados afirmarem ter vergonha do seu trabalho. Entre as dificuldades apontadas na execução do trabalho, os operários da UTL referem-se a atitudes da comunidade (mistura de lixo), enquanto os catadores individuais fazem alusão à inação do poder público (abandono, desrespeito). Os operários da UTL não se sentem abandonados pelo poder público, pois são funcionários com direitos trabalhistas assegurados, enquanto os catadores individuais não desfrutam desse direito social.

$\mathrm{Na}$ análise comparada dos dados, percebem-se ainda algumas semelhanças entre os 
dois grupos: a boa relação no trabalho e a convivência pacífica com os colegas de profissão. Os dois grupos registram esse caráter de harmonia e coesão social, omitindo os conflitos do cotidiano. Esse fato pode estar relacionado à aceitação social que esses grupos precisam exprimir para garantir a importância de sua atividade como algo essencial à sociedade.

Os dois grupos, no entanto, têm diferentes percepções sobre a visão que a comunidade constrói sobre quem trabalha com resíduos. Enquanto os operários da UTL observam a existência de preconceito, os catadores individuais sentem-se aceitos. Os dois grupos concordam que a coleta seletiva deve melhorar, já que a comunidade tende a não separar devidamente os resíduos. Enquanto consumidores, os dois grupos reaproveitam alguns resíduos, reutilizando-os.

Com relação ao meio ambiente, este é percebido como natureza intocada pelos operários da UTL. Já entre os catadores de rua, sobressai-se a ideia de limpeza. Esse dado pode ser relacionado às possíveis pressões que os catadores sofrem do poder público para manter a cidade "organizada e limpa" depois da coleta. Outro ponto de convergência é que os dois grupos identificam a questão do lixo como um problema regional, que o catador ajuda a minimizar.

Comparativamente, percebeu-se que os catadores que atuam na UTL sentem-se excluídos pela sociedade devido ao preconceito que percebem em relação ao seu trabalho, e, mesmo estando incluídos no Programa Brasil Joga Limpo, demonstraram estar excluídos das informações sobre o seu papel nesse Programa. Esse grupo sente-se incluído no universo do trabalho e está mais próximo dos serviços públicos essenciais providos pelo Estado. Os catadores da UTL também se sentem incluídos como atores que têm um importante papel ambiental. Já os catadores que atuam na rua, individualmente, sentem-se abandonados pelo Estado, excluídos do acesso ao trabalho formal e suas garantias, assim como demonstraram sentirem-se mais distantes do acesso aos serviços essenciais. Apesar de excluídos do trabalho formal, sentem-se incluídos no universo de trabalho, já que apontaram que a catação é um espaço de construção da dignidade e de desempenho do seu papel de agentes ambientais. Eles sentem-se, ainda, in- cluídos na comunidade a partir da boa relação que afirmam ter com os moradores.

Apesar da análise dos dados apontar maior precariedade das condições de vida dos catadores individuais, em contraponto à realidade vivida entre os operários da UTL, nos dois grupos o trabalho com a catação acaba gerando a inclusão desses atores na cadeia produtiva que se organiza a partir dos resíduos sólidos domésticos, cadeia esta que se organiza, paradoxalmente, a partir da exclusão de diferentes sujeitos do trabalho formal e da precarização das formas de trabalho que marca a sociedade globalizada.

A proposta do poder público de organizar os catadores que trabalham individualmente, em Estrela/RS, por meio de programas institucionais, como a experiência do Programa Brasil Joga Limpo, apesar da sua amplitude relativa (incorpora a minoria desse segmento), denota alguns indicadores positivos quanto ao seu conteúdo (aquisição dos direitos trabalhistas por um pequeno grupo, discussão sobre as questões ambientais e a alteração das práticas cotidianas relacionadas ao tema).

A parceria entre município e governo federal possibilita a ampliação dos recursos utilizáveis na UTL, bem como a qualificação dos trabalhadores que ali atuam. Mas, e quanto aos catadores individuais, que vivem na absoluta informalidade e precariedade social? O Programa Brasil Joga Limpo é uma política pública de gestão dos resíduos sólidos domésticos que previa a inclusão também desse grupo, o que acontece de forma frágil, se comparada com a realidade dos catadores que atuam na UTL. Isso se deve, em parte, às dificuldades dos gestores públicos de se comunicarem com esse grupo social, de modo a seduzi-lo para participar do Fórum Lixo e Cidadania, o qual se coloca, teoricamente, como uma instância efetiva de construção da cidadania.

Na prática, nenhum dos dois grupos estudados supera a tradição sociopolítica do Estado, que mantém políticas pontuais de inclusão, não indo além disso, o que deixa transparecer a prevalência de uma cidadania formal, que se explicita nas suas próprias condições de trabalho informal. No entanto, podem-se observar novas possibilidades de inserção social entre os catadores dos dois grupos. Esses trabalhadores visualizam a importância do papel ambiental 
que desempenham diariamente. Entretanto, eles ainda não podem ser considerados agentes de cidadania ambiental, no sentido trazido pelos autores citados (LOUREIRO, 2002; GUTIÉRREZ; PRADO, 1999, dentre outros), os quais estão atrelados: à justiça social, ao desenvolvimento econômico em um contexto de globalização, à sua característica de construção permanente, ao senso de pertencimento do indivíduo a uma sociedade, à participação em organizações sociais, à tomada de consciência individual e coletiva das responsabilidades tanto locais e comunitárias quanto globais, à responsabilidade social e em relação à natureza, à percepção das inter-relações entre instâncias sociais, econômicas, políticas públicas, qualidade de vida, à autonomia e apropriação do destino de sua própria vida, à capacidade de compreender e recriar o novo contexto socioambiental, à exigência de relacionar a ecologia interna e externa, à necessidade de incluir a subjetividade, a emoção, o sentimento.

Nesse sentido, as experiências dos catadores nas suas relações com o trabalho do recolhimento e separação de resíduos têm transformado essas pessoas em novos atores sociais, mas não em novos agentes da cidadania ambiental da sociedade planetária. E como poderia? Qual cidadania é possível nesse contexto que ainda obriga muitos a migrarem para cidades mais "desenvolvidas" em busca de resíduos de "melhor qualidade"? Como é possível que esses trabalhadores ainda sintam-se incluídos quando a maioria dos moradores não separa devidamente os resíduos? Afinal de contas, quais direitos estão realmente garantidos (civis/liberdade, políticos/participação, sociais/bem-estar), se é preciso catar para sobreviver dos restos da sociedade de consumo?

Essas questões talvez apontem para o elo que liga a estrutura social patriarcal brasileira ao processo de urbanização/industrialização ao regime ditatorial e à conjuntura atual. Tal elo pode ser entendido como a prevalência de uma cultura política elitista, marcada pela tradicionalização de práticas sociais excludentes e precárias, tais como: concentração de riquezas, apatia social, escravidões, exclusões e autoritarismos de diferentes naturezas, atrelamento do Estado às elites e projetos de desenvolvimento assentados na lógica capitalista insustentável.
A modernização conservadora tende a excluir parte dos trabalhadores dos frutos do desenvolvimento econômico, apesar da demanda por justiça social impulsionar novas práticas no campo ambiental. A tradição autoritária e excludente fez com que o Estado brasileiro incorporasse uma cultura republicana elitista em detrimento do Estado democrático social. Conforme Nascimento (2003), daí decorre a globalização da pobreza, mas não da riqueza. Desse processo resulta o aumento da pobreza também nas pequenas cidades, uma vez que a urbanização é acompanhada de processos de exclusão social. Tal cenário foi evidenciado no município de Estrela/RS, onde o Programa Brasil Joga Limpo pode ser considerado uma iniciativa pontual, com resultados parciais quanto à inclusão social. Trata-se, sem dúvida, de uma iniciativa com potencialidade de ampliação, dependendo, entretanto, das estratégias dos gestores públicos para possibilitar a construção de práticas sociais pautadas no exercício da cidadania, na autonomia dos indivíduos, na justiça social, no equilíbrio ecológico e na solidariedade para com as gerações futuras.

\section{Considerações finais}

O artigo contextualizou o cenário social, histórico e político nacional para que fosse possível compreender as marcas culturais da constituição dos processos de desigualdade na sociedade brasileira. O país ainda caracteriza-se fortemente como uma sociedade verticalizada, excludente, com fragilidade institucional. Quadro este que mostra estar agravando-se devido às mudanças no mercado de trabalho decorrentes do processo da globalização, o que se reflete diretamente na realidade social dos catadores.

Somam-se a essas dificuldades novos desafios que surgem no horizonte relacionado à produção e transformação dos resíduos. Uma discussão atual refere-se à proposta, que vem ganhando força, de usar os resíduos como matéria-prima para a produção de energia, prometendo transformar o que é considerado lixo em um produto disputado entre setores que, historicamente, têm forças desiguais. Caso essa possibilidade tecnológica se concretize, a situação econômica vivida pelos catadores tende a se agravar, gerando um novo elemento 
de exclusão, decorrente da supremacia das soluções ambientais baseadas em premissas econômicas e tecnológicas em detrimento dos interesses sociais.

Outro aspecto abordado no artigo foi o surgimento do ambientalismo no país, com o movimento dos catadores representando seu avanço ao ampliar suas pautas (de preservação e conservação ecológica) com a incorporação das questões de justiça social e econômica. Nesse sentido, a problemática situação vivida pelos catadores representa não apenas um tema relativo ao desenvolvimento sustentável, mas essencialmente um elemento de desenvolvimento humano. Esse aspecto é reconhecido pela Política Nacional de Resíduos Sólidos, apontando para a necessária inclusão formal desse grupo social na cadeia de resíduos, incentivando sua organização cooperativada, de modo a reverter seu quadro de exclusão.

Algumas questões surgem, mas precisam de tempo para serem respondidas. A Política Nacional de Resíduos Sólidos se efetivará como ação social ou ficará como uma utopia, a exemplo de outras políticas ambientais? Quais estratégias sociais são necessárias pra mobilizar os catadores que atuam individualmente nas ruas para sua organização em cooperativas de trabalho? Como atender às proposições da Política Nacional de Resíduos Sólidos e equalizar disputas de interesses em torno dos resíduos, respeitando as necessidades dos catadores? Cabe aos pesquisadores que se debruçam sobre essa temática estarem atentos às transformações nesse cenário multifacetado em que os catadores estão imersos, investigando como velhas exclusões e novas facetas da cidadania se forjam com o tempo.

\section{Referências}

BOBBIO, N. Teoria geral da política: a filosofia política e a lição dos clássicos. Rio de Janeiro: Campus, 2000.

CASTRO. R. S. de.; BAETA, A. M. B. Autonomia intelectual: condição necessária para o exercício da cidadania. In: LOUREIRO, C. F. B.; LAYRARGUES, P. P. (Org.). Educação ambiental: repensando o espaço da cidadania. São Paulo: Cortez, 2002.
FREYRE, G. Casa-grande \& senzala: formação da família brasileira sob o regime da economia patriarcal. São Paulo: Global, 2004.

FUNDAÇÃO DE ECONOMIA E ESTATÍSTICA. Índice de desenvolvimento socioeconômico. Porto Alegre: FEE, 2007. Disponível em: <http://www. fee.tche.br/sitefee/pt/content/estatisticas/pg_idese. php?ano=2005>. Acesso em: 22 jul. 2008.

Vale do Taquari. Porto Alegre: FEE, 2008. Disponível em: <http://www. fee.tche.br/ sitefee/pt/content/resumo/pg_coredes_detalhe. php? corede $=$ Vale + do + Taquari $>$.Acesso em: 20 jul. 2008.

Índice de desenvolvimento socioeconômico (IDESE): texto completo. Porto Alegre: FEE, 2008. Disponível em: <http://www.fee.tche.br/sitefee/pt/ content/estatisticas/pg_idese.php>. Acesso em: 13 jan. 2009.

GUTIÉRREZ, F.; PRADO, C. Ecopedagogia e cidadania planetária. São Paulo: Cortez, 1999.

HOLANDA, S. B. Raízes do Brasil. Rio de Janeiro: J. Olympio, 1984.

INSTITUTO BRASILEIRO DE GEOGRAFIA E ESTATISTICA. Cidades. Rio de Janeiro: IBGE, 2007. Disponível em: <http://www.ibge.gov.br/cidadesat/ topwindow. htm?1>. Acesso em: 18 jul. 2008.

LEIS, H. R; D'AMATO, J. L. O ambientalismo como movimento vital: análise de suas dimensões histórica, ética e vivencial. In: CAVALCANTI, C. (Org.). Desenvolvimento e natureza: estudos para uma sociedade sustentável. São Paulo: Cortez, 1995.

LOUREIRO, C. F. B. Educação ambiental e movimentos sociais na construção da cidadania ecológica e planetária. In: LOUREIRO, C. F. B.; LAYRARGUES, P. P.; CASTRO, R. S. de. (Orgs.). Educação ambiental: repensando o espaço da cidadania. São Paulo: Cortez, 2002.

MARSHALL, T. H. Cidadania, classe social e status. Rio de Janeiro: Zahar, 1967.

MAZZARINO, J. M. Tecelagens comunicacionaismidiáticas do movimento socioambiental. Lajeado: Univates, 2013. Disponível em: <http://www.univates. $\mathrm{br} / \mathrm{media} / \mathrm{manual} /$ tecelagens_ebook.pdf $>$. Acesso em: 23 jan. 2009.

MIGUELES, C. (Comp.). Antropologia do consumo: casos brasileiros. Rio de Janeiro: FGV, 2007. 
NASCIMENTO, E. P. Dos excluídos necessários aos excluídos desnecessários. In: BURSZTYN, M. No meio da rua: nômades, excluídos e viradores. Rio de Janeiro: Garamond, 2003.

SADER, E. Quando novos personagens entraram em cena: experiências e lutas dos trabalhadores da Grande São Paulo, 1970-1980. Rio de Janeiro: Paz e Terra, 1988.

SANTOS, B. de S. (Org.). Produzir para viver: os caminhos da produção não capitalista. Porto: Afrontamento, 2003.

SOSNISKI, C. Repensando fronteiras entre o lixo e o corpo: estudo etnográfico sobre o cotidiano de recicladores, catadores e carroceiros na llha Grande dos Marinheiros. 2006, 130 f. Dissertação (Mestrado em Antropologia Social) - Universidade Federal do Rio Grande do Sul, Porto Alegre, 2006.

VERDUM, R. O ciclo do papel, da coleta ao processamento: personagens e estrutura. In: SUERTEGARAY, D. M. A.; BASSO, L. A.; VERDUM, R. Ambiente e lugar no urbano: a grande Porto Alegre. Porto Alegre: UFRGS, 2000.

VERGARA, S. C. Projetos e relatórios de pesquisa em administração. São Paulo: Atlas, 2004.

VIOLA, E. O movimento ambientalista no Brasil (19711991): da denúncia e conscientização pública para a institucionalização e o desenvolvimento sustentável. In: GOLDENBERG, M. (Coord.). Ecologia, ciência e política: participação social, interesses em jogo e luta de idéias no movimento ecológico. Rio de Janeiro: Revan, 1992.

. O movimento ecológico no Brasil (19741986): do ambientalismo à ecopolítica. In: VIOLA, E. A. et al. Ecologia e política no Brasil. Rio de Janeiro: Espaço e Tempo, 1987. 